\title{
Investigating the Management of the Formation of Habermas Public Sphere Theory in Instagram and Telegram Networks
}

\section{Investigando la gestión de la formación de la teoría de la esfera pública de Habermas en redes de Instagram y Telegram}

\author{
Ali Asadnezhad \\ Ph.D Student, Department of Communication Sciences, Ardabil Branch, Islamic Azad \\ University, Ardabil, Iran. \\ ORCID ID: https://orcid.org/0000-0001-8571-2944

\begin{abstract}
Nahid Kordi
Tehran, Iran.

ORCID ID: https://orcid.org/0000-0003-3140-7981

\section{Ali Jafari}

Department of Communication Sciences, Ardabil Branch, Islamic Azad University, Ardabil, Iran

ORCID ID: https://orcid.org/0000-0001-9204-8105
\end{abstract} \\ Department of Communication Sciences, East Tehran Branch, Islamic Azad University,
}

Received 09-08-20 Revised 10-10-20

*Correspondence

Email: kordinahid1@gmail.com
Accepted 12-12-20 On line 03-08-21

Cite as:

Asadnezhad, A., Kordi, N., \& Jafari, A. (2021). Investigating the Management of the Formation of Habermas Public Sphere Theory in Instagram and Telegram Networks. Propósitos y Representaciones, 9 (SPE3), e1115. Doi: http://dx.doi.org/10.20511/pyr2021.v9nSPE3.1115 


\section{Summary}

The purpose of this study is to examining the management of the formation of Habermas public Sphere theory in Instagram and Telegram networks. The research method is survey. Statistical Society of this research is the users of social networks (telegram and Instagram). according to the Cochrane formula statistical sample is 384 people. Using purposive non-random sampling method the Statistical samples was selected and the data were analyzed by Pearson correlation method. The results showed that There is a significant relationship between free access to the Internet and social networks, rational critique of political economic social and cultural issues, rational criticism of the government, free dialogue and the formation of the public sphere. There is a difference between the formation of the public Sphere in social networks and the level of education. There is a difference between the formation of the public Sphere in social networks and individuals' age, but There is not much difference between the formation of the public Sphere in social networks and gender.

Keywords: Management, Social Networks, Telegram and Instagram, Habermas Public Sphere.

\section{Resumen}

El propósito de este estudio es examinar la gestión de la formación de la teoría de la esfera pública de Habermas en las redes de Instagram y Telegram. El método de investigación es la encuesta. La Sociedad Estadística de esta investigación son los usuarios de las redes sociales (Telegram e Instagram). según la fórmula de Cochrane, la muestra estadística es de 384 personas. Utilizando el método de muestreo no aleatorio intencional, se seleccionaron las muestras estadísticas y los datos se analizaron mediante el método de correlación de Pearson. Los resultados mostraron que existe una relación significativa entre el libre acceso a Internet y las redes sociales, la crítica racional de los temas político-económicos sociales y culturales, la crítica racional al gobierno, el diálogo libre y la formación de la esfera pública. Existe una diferencia entre la formación de la Esfera pública en las redes sociales y el nivel de educación. Existe una diferencia entre la formación de la Esfera pública en las redes sociales y la edad de los individuos, pero no hay mucha diferencia entre la formación de la Esfera pública en las redes sociales y el género.

Palabras clave: Gestión, Redes Sociales, Telegram e Instagram, Esfera Pública de Habermas

\section{Introduction}

The right to know is one of the citizenship rights with wide dimensions. Access to the right information on the domestic and international issues and media freedoms, dissemination, the The Internet and related technologies, more than any other medium before itself, and especially since the time when people were only able to communicate directly and face to face, allow people to cross and overcome the boundaries of time and space. This medium also, more than any other medium, create a type of communication which the most important features of that are being horizontal, interactive, networked and social. On the other hand, people can access to any kind of information at any time and place through these technologies. moreover, people have the ability to simultaneously produce and consume content; Thus, the Internet and related technologies have changed the way people gather and interact with each other, have changed the way people access to information and even how people react to information (especially political and social information). In this context, it is argued that the Internet and subsequently cyberspace, facilitated what Habermas defined as the public domain; That is, where public opinion is formed. In describing of the public domain, Habermas explains a situation in which individuals can discuss critical issues and gain knowledge of public issues. in such space public opinion is formed; a public and shared space in which decisions are made through dialogue. People "in the ideal state of dialogue "talk to others to understand which ideas and values are valid and not to use others as 
tools to realize their ideas (Khaniki et al., 2017: 103). According to Habermas, the public domain was a product of the main features of the growing England capitalist society in eighteenth-century. The decisive factor was that the capitalist entrepreneurs had managed their wealth which become able to fight for independency from the government and the church, so they got what they wanted. Before that, public life was dominated by the clergy and the court, whose usual focus was on the ceremonial display of feudal relations. But with the wealth growth of those who sought capital, this superiority was shaken.

On the one hand, this hesitation resulted from the fact that capitalism provided more support to the world of "words", theatre, art, coffee house, fiction, etc., thus reducing the severity of their dependence on their supporters and forming an independent sphere of them. They became traditional powers that were committed to criticism and critique.

Habermas says that dialogue and discussion turned into criticism and sweet words into arguments (Mehdi zadeh, 2004: 3). The extension of the Internet and mobile phones, along with the management of the usage of media convergence facilities, caused social networks to be welcomed by Iranian audiences, so the expansion of new media and its various forms, including social networks, has caused a change in the traditional public domain. Due to the filtering of social networks (Facebook, Telegram, etc.) in Iran and the diversity of these networks' space, freely many young people, for lack of public arena, for communication and exchanging information have become members of these networks.

Given the new media environment that has been affected by the decentralization of media and the pervasiveness of citizens' access to it the present study seeks to answer the question that Habermas's public Sphere theory management on social networks such as (Instagram and Telegram) social networks What has been the vision of cyberspace users?

\section{Research background}

Seyed Alavi and Naqib alsadat (2011), in a study entitled "Public Sphere in cyberspace", found that three independent variables of the public sphere have been formed by the perspective of communication science and political science experts in the country's universities. The findings of the two researchers showed that public sphere theory could be applied in the virtual sphere. However, cyberspace and computer-mediated communication characteristics have made the public sphere a multifaceted and fragmented space that differs from the traditional public sphere model.

Yazd khasti et al. (2013), in a study entitled "Public Sphere and conversation in cyberspace of virtual social networks", found that although the promotion of communication and information exchange in virtual social networks enhances the possibility of conversation, it is also limited and distorting. The intended limitations arise from the unequal distribution of possibilities associated with such technologies, and the particular state of the virtual public domain also distorts intercultural dialogues. Virtual social networks limit and distort dialogue between cultures by creating the public and virtual domain.

Yazd khasti et al. (2013), in another study entitled "Analysis the content of Facebook social network pages and groups with the theory of Habermas public Sphere ", found that although Facebook has increased access to information among Iranian users, but overproduction of content eventually leads to fragmentation and multiplication of reality.

Ghani Rad et al. (2009), in a study entitled "Conflicting approaches to the development of the public Sphere in cyberspace", showed that despite some capacity of cyberspace to form the public Sphere, are important challenges such as digital divide, polarization and fragmentation in cyberspace, anonymity, and ultimately the weakening of real social ties. They also pointed out that a more detailed study of the relationship between cyberspace and the public Sphere requires the avoidance of technological determinism and consideration of the institutional and social context and a comparative study of the various social and institutional contexts.

Najafi and Nyblom (2015), in a study entitled "Iranian youth and the Internet", found that the Internet has affected the public and private Sphere and by creating its domain (virtual domain) 
that has created a space where people can escape the limitations of the public Sphere and express themselves privately.

\section{Theoretical literature}

Habermas Public Domain Theory: Habermas uses the term of the public Sphere to refer to the social Sphere in which individuals engage in normative positions and orientations through conversation, communication, and reasoning based on intellection that leaves informative and rationalizing effects on exercising government power.

In other words, individuals in the public Sphere (social domain) through communication, reasoning, being in conditions free from any pressure and urgency, accessible and interactive awareness in equal conditions for all parties participating in the public domain.

To produce a set of value and normative behaviours, positions and orientations that ultimately act as an effective tool for influencing government behaviour and rejection, especially in rationalizing government power.

What draws Habermas attention to the public domain is the importance of this concept as the basis for a critique of society based on democratic principles. Thus, the public domain is an arena in which individuals have gathered to participate in free and open dialogue (Habermas, 2013: 210). According to Habermas, the public domain is a multidisciplinary realm and the meeting place of various ideas and thoughts and the space for the accessible design of public issues that form reasoning and intellection about them. Finally, the public will (Ibid: 148).

Habermas's public Sphere is rooted in the private domain's interests, which is formed through citizens' dialogue and debate on public issues. In this way, in any conversation, private individuals come together to form public bodies. In such a situation, individuals' behaviour is no longer like that of business people or professional persons doing personal affairs, nor are they like members of a constitutional system under the legal constraints of a government bureaucracy. In this area, citizens in an uncontrolled form, by guaranteeing freedom of association and freedom of expression and dissemination of their opinions, exchange views on public interest issues and act as a public body (Bustani and Poladi, 2018: 25).

In this public body, issues and topics of public interest can be discussed, an area in which differences and conflict of opinion and thoughts can be resolved through logical discussion and reasoning, and not through the details which are embedded or by appealing to the traditional rules and details issued by traditions and customs.

The public domain is the bright domain as opposed to the dark domain of power and private interests. The more the public domain expands and the more power is absorbed, the more field of rationalization of government and politics expands. The public domain is the space in which "public opinion" is formed. According to Habermas, the best description that can be given of public opinion is a network for exchanging information and various views that are formed based on the coming together of different communication, within which this information is received, refined and combined and Give direction to the public will. (Ibid: 26).

Referring to Habermas's views, O'Brien lists the three main elements of the public domain as follows:

The public Sphere needs a place for discussion accessible to all where it is possible to express and debate social experiences and views; In the public domain, confrontation with views and points of view takes place through rational and logical debate. This means that "rational" political choice is possible only when the public domain, in the first place, offers explicit knowledge and understanding of the possible options; So that each person can choose from those options. The media should provide the broadest possible range of frameworks or perspectives so that citizens know what they have not chosen; Regular and critical review and monitoring of government policies is the main task of the public domain (Khaniki et al., 2017: 113).

\section{Methodology}

The research is based on the mensuration and rooting method. This research is descriptive, but in terms of the purpose, it is practical research. In this research, after conducting library studies, 
complete and comprehensive compilation of theoretical literature and research background, a questionnaire has been designed and compiled for this research's questions and hypotheses, theories related to this study, and finally distributed among the respondents. This research's statistical population includes the audiences (cyberspace users). according to Cochran's formula, its statistical sample is equal to 384 people. Therefore, by following this formula, in this research as a statistical sample, 384 people have completed a questionnaire. The study sample was selected by using the purposive non-random sampling method.

\section{Results}

Descriptive results

Frequency distribution by gender of respondents

Table 1. Frequency distribution by gender of respondents

\begin{tabular}{|c|c|c|c|}
\hline Row & Gender & Quantity & Percent \\
\hline 1 & Male & 242 & 63.0 \\
\hline 2 & Female & 142 & 37.0 \\
\hline 3 & Sum & 384 & 100.00 \\
\hline
\end{tabular}

Of the total respondents in terms of gender, 242 people $(63.0 \%)$ were men, and 142 people $(37.0 \%)$ were women.

\section{Frequency distribution according to the age of the respondents}

Table 2. Frequency distribution according to the age of the respondents

\begin{tabular}{|c|c|c|c|}
\hline Row & Age & Quantity & Percent \\
\hline 1 & $20-30$ & 70 & 18.2 \\
\hline 2 & $30-40$ & 129 & 33.6 \\
\hline 3 & $40-50$ & 117 & 30.5 \\
\hline 4 & More than 50 & 67 & $17 / 4$ \\
\hline 5 & Without answer & 1 & 0.3 \\
\hline 6 & sum & 384 & 100.00 \\
\hline
\end{tabular}

Of the total respondents in terms of age, 70 people equalled $18.2 \%$ between 20 and 30 years old, 129 people equalled $33.6 \%$ between 30 and 40 years old, 117 people equalled $130.5 \%$ between 40 and 50 years old and $6717.4 \%$ were over 50 years old, and $0.3 \%$ did not answer this question.

\section{Frequency distribution according to respondents' education}

Table 3. Frequency distribution according to the education of the respondents

\begin{tabular}{|c|c|c|c|}
\hline Row & Education & Quantity & Percent \\
\hline 1 & Diploma & 8 & 2.1 \\
\hline 2 & Associate Degree & 21 & 5.5 \\
\hline 3 & Bachelor degree & 157 & 40.9 \\
\hline 4 & Master degree & 133 & 34.6 \\
\hline 5 & P.HD & 64 & 16.7 \\
\hline 6 & Without answer & 1 & 0.3 \\
\hline 7 & Sum & 384 & 100.00 \\
\hline \multicolumn{3}{|l}{} \\
\hline
\end{tabular}

Of the total respondents, 8 (2.1\%) have a diploma, 21 (5.5\%) have an Associate Degree, 157 (40.9\%) have a Bachelor degree, 133 (34.6\%) have a Master degree and 64 (7.7\%). 16\% have a doctorate, and one person $(0.3 \%)$ did not answer this question. 
There is a relationship between free access to the Internet and the formation of the public Sphere.

Table 4. the relationship between Free Internet access and the formation of the public Sphere.

\begin{tabular}{|c|c|c|c|c|}
\hline $\begin{array}{c}\text { Free access to the Internet and the } \\
\text { formation of the public Sphere. }\end{array}$ & $\begin{array}{c}\text { Degree of } \\
\text { correlation }\end{array}$ & $\begin{array}{c}\text { Significance } \\
\text { level }\end{array}$ & quantity & results \\
\hline & 0.83 & 0.000 & 384 & confirmed \\
\hline
\end{tabular}

There is a significant relationship between free internet access and Habermas public Sphere formation, and the amount of relationship is $0.83 \%$, which shows a powerful relationship between these two variables. In other words, the more complimentary internet access, the more public Sphere is formed.

The Pearson test results indicate that with $99 \%$ confidence and an error level of less than $1 \%$, there is a significant relationship between the two variables of free Internet access to the audience and the Habermas public domain's formation. In this regard, the correlation coefficient is equal to 0.83 , which is a very positive relationship.

\section{The second hypothesis}

There is a relationship between free access to social networks and the formation of the public Sphere.

Table 5. the relationship between Free access to social networks and the formation of the public Sphere.

\begin{tabular}{|c|c|c|c|c|}
\hline $\begin{array}{c}\text { Free access to the social } \\
\text { networks and the formation of } \\
\text { the public Sphere. }\end{array}$ & $\begin{array}{c}\text { Degree of } \\
\text { correlation }\end{array}$ & $\begin{array}{c}\text { Significance } \\
\text { level }\end{array}$ & Quantity & results \\
\hline & 0.80 & 0.000 & 384 & confirmed \\
\hline
\end{tabular}

There is a significant relationship between free access to social networks and the formation of Habermas public Sphere. The relationship is $0.80 \%$, which indicates a powerful relationship between these two variables. In other words, the more open access to social networks, the more public Sphere is formed.

The Pearson test results indicate that with $99 \%$ confidence and an error level of less than $1 \%$, there is a significant relationship between the two variables of free access to social networks and the formation of the Habermas public Sphere. In this regard, the correlation coefficient is equal to 0.80 , which is a very positive relationship.

\section{The third hypothesis}

There is a relationship between social networks and public Sphere formation.

Table 6. the relationship between Use of social networks and public Sphere formation

\begin{tabular}{|c|c|c|c|c|}
\hline $\begin{array}{c}\text { Using social networks (Telegram and } \\
\text { Instagram) and forming a public } \\
\text { Sphere }\end{array}$ & $\begin{array}{c}\text { Degree of } \\
\text { correlation }\end{array}$ & $\begin{array}{c}\text { Significance } \\
\text { level }\end{array}$ & Quantity & results \\
\hline & 0.85 & 0.000 & 384 & confirmed \\
\hline
\end{tabular}

There is a significant relationship between the use of social networks (Telegram and Instagram). The formation of Habermas public Sphere and the relationship is $0.85 \%$, which shows that there is a powerful relationship between these two variables; in other words, the more use of social networks (Telegram and Instagram), the more the public Sphere is formed.

The Pearson test results indicate that with $99 \%$ confidence and an error level of less than $1 \%$, there is a significant relationship between the two variables of using social networks (Telegram and Instagram) and the formation of the Habermas public Sphere. In this regard, the correlation coefficient is equal to 0.85 , which is a very positive relationship. 


\section{The fourth hypothesis}

There is a relationship between the critique of public power management (government) by social media audiences (Telegram and Instagram) and the formation of the public Sphere.

Table 7. Management of public power (government) by social media audiences

\begin{tabular}{|c|c|c|c|c|}
\hline $\begin{array}{c}\text { The relationship between public } \\
\text { power management (government) } \\
\text { criticism by social media audiences } \\
\text { (Telegram and Instagram) and the } \\
\text { formation of the public Sphere }\end{array}$ & $\begin{array}{c}\text { Degree of } \\
\text { correlation }\end{array}$ & $\begin{array}{c}\text { Significance } \\
\text { level }\end{array}$ & Quantity & results \\
\hline & 0,87 & 0.000 & 384 & Confirmed \\
\hline
\end{tabular}

There is a significant relationship between the critique of public power management (government) by the audience of social networks (Telegram and Instagram). Habermas' public Sphere formation and the relationship is $0.87 \%$, which shows a powerful relationship between these two variables. The more criticism of public power (government) by the audience of social networks (Telegram and Instagram), the more public Sphere formation.

The Pearson test results indicate that with $99 \%$ confidence and error level less than $1 \%$, there is a significant relationship between the two variables of public power management (government) criticism by social media audiences (Telegram and Instagram) and the formation of Habermas public Sphere. In this regard, the correlation coefficient is equal to 0.87 , which is a very positive relationship.

\section{Fifth Hypothesis}

There is a relationship between a reasonable and rational critique of the management of political, economic, social and cultural issues in social networks (Telegram and Instagram) and the public Sphere 's formation.

Table 8. Rational and reasonable critique of the management of political, economic, social and cultural issues in social networks (Telegram and Instagram)

\begin{tabular}{|c|c|c|c|c|}
\hline $\begin{array}{c}\text { reasonable and rational critique of the } \\
\text { management of political, economic, } \\
\text { social and cultural issues in social } \\
\text { networks (Telegram and Instagram) } \\
\text { and the formation of the public Sphere }\end{array}$ & $\begin{array}{c}\text { Degree of } \\
\text { correlation }\end{array}$ & $\begin{array}{c}\text { Significance } \\
\text { level }\end{array}$ & quantity & results \\
\hline & 0.89 & 0.000 & 384 & Confirmed \\
\hline
\end{tabular}

There is a significant relationship between the rational and rational critique of the management of political, economic, social and cultural issues in social networks (Telegram and Instagram) and the Habermas public sphere's formation. The relationship is $0.89 \%$, which shows a powerful connection between the two. There is a variable. In other words, the more logical and rational critique of political, economic, social and cultural issues in social networks (Telegram and Instagram), the more the formation of the public sphere.

The results of the Pearson test indicate that with $99 \%$ confidence and less than $1 \%$ error level, there is a significant relationship between the two variables of a rational and rational critique of political, economic, social and cultural issues management in social networks (Telegram and Instagram) and the formation of public Sphere. Habermas, there is a meaningful relationship. In this regard, the correlation coefficient is equal to 0.87 , which is a very positive relationship.

\section{Hypothesis 6}


There is a relationship between bilateral and free dialogue between the audience (everyone) and government officials on social networks (Telegram and Instagram) and the public Sphere's formation.

Table 9.a bilateral and free conversation of the audience (everyone) with government officials on social networks (Telegram and Instagram)

\begin{tabular}{|c|c|c|c|c|}
\hline $\begin{array}{c}\text { bilateral and free dialogue between the } \\
\text { audience (everyone) and government } \\
\text { officials on social networks (Telegram } \\
\text { and Instagram) and the formation of the } \\
\text { public Sphere. }\end{array}$ & $\begin{array}{c}\text { Degree of } \\
\text { correlation }\end{array}$ & $\begin{array}{c}\text { Significance } \\
\text { level }\end{array}$ & quantity & results \\
\hline & 0.89 & 0.000 & 384 & Confirmed \\
\hline
\end{tabular}

There is a significant relationship between the bilateral and free conversation of the audience (everyone) with government officials on social networks (Telegram and Instagram). The Habermas public Sphere formation and the relationship is $0.89 \%$, which shows a very strong relationship between these two variables. In other words, the more bilateral and free dialogue of the audience (everyone) with government officials on social networks (Telegram and Instagram), the more the formation of the public Sphere is. The results of the Pearson test indicate that with $99 \%$ confidence and an error level of less than $1 \%$, there is a significant relationship between the two variables of bilateral conversation and free audience (everyone) with government officials on social networks (Telegram and Instagram) and the formation of Habermas public Sphere. There is a meaningful relationship. In this regard, the correlation coefficient is equal to 0.89 , which is a very positive relationship.

\section{Analysis of variance (changes)}

Analysis of variance between education and the formation of the public Sphere

Table 10. Analysis of variance between the level of education and the formation of the public domain

\begin{tabular}{|c|c|c|c|c|c|c|}
\hline Dependent variable & $\begin{array}{c}\text { Independe } \\
\text { nt variable }\end{array}$ & Class & quantity & average & F & $\begin{array}{c}\text { Significan } \\
\text { ce level }\end{array}$ \\
\hline & & Diploma & 8 & $42 / 0$ & & $0 / 000$ \\
\hline $\begin{array}{c}\text { formation of the } \\
\text { public Sphere }\end{array}$ & $\begin{array}{c}\text { Education } \\
\text { level }\end{array}$ & Associate Degree & 22 & $43 / 40$ & & \\
\hline & & Bachelor degree & 158 & $48 / 45$ & & \\
\hline & & Master degree & 133 & $50 / 72$ & & \\
\hline & & PHD & 67 & $54 / 92$ & & \\
\hline
\end{tabular}

There is a difference between the formation of the public Sphere in social networks and the level of education; as it is clear from the obtained averages, the more educated people are, the greater the tendency to form the public Sphere in social networks. In other words, there is a significant difference in the level of education and the tendency to form a public domain in social networks, and the higher education, the greater tendency to form a public Sphere in a social network.

Analysis of variance of gender relationship and formation of Habermas public domain

Table 11. Analysis of variance of gender relations and the formation of the public domain

\begin{tabular}{|c|c|c|c|c|c|c|}
\hline Dependent variable & $\begin{array}{c}\text { Independent } \\
\text { variable }\end{array}$ & Class & quantity & average & F & $\begin{array}{c}\text { Significance } \\
\text { level }\end{array}$ \\
\hline formation of the public Sphere & Gender & Male & 242 & 49.60 & 79.0 & 0.000 \\
\hline & & female & 142 & 50.40 & & \\
\hline
\end{tabular}


There is not much difference between the formation of the public Sphere in social networks and gender; as it is clear from the obtained averages, there is not much difference in terms of gender and the tendency to form the public Sphere in social networks.

Analysis of variance of the relationship between age and the formation of Habermas public Sphere

Table 12. Analysis of variance between age and the formation of the public domain

\begin{tabular}{|c|c|c|c|c|c|c|}
\hline $\begin{array}{c}\text { Dependent } \\
\text { variable }\end{array}$ & $\begin{array}{c}\text { Independent } \\
\text { variable }\end{array}$ & Class & quantity & average & F & $\begin{array}{c}\text { Significance } \\
\text { level }\end{array}$ \\
\hline $\begin{array}{c}\text { formation of the } \\
\text { public Sphere }\end{array}$ & Age & $20-30$ & 70 & 49.32 & 3.504 & 0.000 \\
\hline & & $40-40$ & 131 & 50.65 & & \\
\hline & & $\begin{array}{c}\text { More } \\
\text { than 50 }\end{array}$ & 70 & 52.18 & & \\
\hline
\end{tabular}

There is a difference between the formation of the public Sphere in social networks and individuals' age. As it is clear from the obtained averages, older people tend to form public Sphere in social networks. In other words, there is a significant difference in age and the tendency to form a public domain in social networks, and the older person has more tendency to form a public Sphere in a social network.

\section{Discussion and conclusion}

This study aims to manage the formation of Habermas public Sphere theory on Instagram and Telegram social networks. Virtual social networks are a type of contact pattern in which a technical base and Internet infrastructure support the interaction and communication between network agents. In these networks, a common goal, interest, or need can be a connecting element that makes related factors feel that they are in a real community, even without a physical presence. If we choose free access to the Internet and social networks, the ability to critique the management of public power (government), rational critique of the management of political, economic, social and cultural issues, a bilateral And free dialogue of audience (everyone) with government officials in social networks (Telegram and Instagram) as the essential components of the formation of the Habermas public domain in the social networks like Telegram and Instagram, so social networks as a new media, a good platform for the emergence and manifestation of each of them. People can talk and interact about their favourite issues through social networks, and through this, public opinion is formed as the voice of the people. Each of them can take action against an issue, a social and political issue.

The expansion of cyberspace has given citizens greater access to various socio-political, cultural, and other information. Cyberspace with features such as lack of control, decentralization, flexibility, easy access to any information, bilateral nature and dialogue, the possibility of publishing any information, and promises an equal world.

This study's findings showed that this space as a kind of virtual public Sphere, despite the unequal distribution of various assets, superficial information, non-continuous issues, the entertaining content, Provided citizens access to various information and the possibility of talking about different topics. These findings are consistent with Ghanirad and Janadleh's (2015) findings, which show that despite some cyberspace containers to form the public Sphere, fundamental challenges such as digital divide, polarization, and fragmentation in cyberspace, anonymity, and ultimately the weakening of real social ties.

Also, Samad Adlipour et al. (2013) conclude that although improving the possibility of virtual social networks to communicate and exchange information in virtual social networks improves the possibility of conversation, it is also limited and distorting. 
The limitation arises primarily from the unequal distribution of possibilities associated with such technologies, and the specific state of the virtual public Sphere also distorts intercultural dialogue. Virtual social networks limit and distort the dialogue between cultures because of the virtual public Sphere they create. Moreover, Rezanian (2010) believes that the Internet, if considered a potential domain, has great potential for the emergence of the public Sphere.

However, in practice, the use of Internet facilities to realize its potential depends on its users' will and the social, political, and cultural conditions of that society.

Furthermore, his findings show that although censorship and restrictions in Iran accompany governmental sites, they do not have the facilities to create discussions among the public.

The private sector mainly creates discussion spaces and facilities for forming virtual communities. Findings obtained during the research, especially in proving the hypotheses, show that although structurally, social networks Instagram and Telegram by providing numerous possibilities such as unlimited ability to publish information, provide comments, file sharing, play videos, etc., opportunities Provides equality for users who can take advantage of its possibilities only by being able to connect to the Internet, possibilities that promise a free and equal society in which everyone can become potential and active members by participating;

Accordingly, the majority of users and audiences agreed with the formation of the public domain (critique of public power (government), logical and rational critique of political, economic, social, and cultural issues management, a bilateral and free dialogue of audiences (all) with government officials on social networks ( Telegram and Instagram (etc.).

Furthermore, as shown in the tables, especially Table 10 shows that with the higher level of education of the audience, demand for the formation of a public domain in cyberspace increases. In other words, many users consider the formation of the public Sphere in social networks as an appropriate approach in confronting and criticizing government power, logical and rational critique of political, economic, social, and cultural issues, bilateral dialogue, and free audience (all) with government officials.

It should be noted that in terms of research that the public Sphere of Habermas has done, one dimension has been about the positive and negative conditions of activity in this cyberspace. However, in this research, we criticize the components and media priorities of the audience. Government performance Given the Habermas public sphere's depth, which is itself a novelty of this research.

\section{References}

Bustani, Mehdi, Pouladi, Kamal. (2017). "A Study of the Elements of the Public Domain in Habermas Thought", Quarterly Journal of Political Science, Year 13, Number 38

Ghanirad, Mohammad Amin, Janadleh, Ali. (2015). Conflicting Approaches to the Development of Public Domain in Cyberspace, New Media Studies, First Year No. 1: 29-68.

Habermas, Jürgen. (2013). Structural Transformation of the Public Domain, translated by Jamal Mohammadi, Tehran: Afkar Publishing.

Kelly, J. \& Etling, B. (2017). Mapping iran's online public: politics and culture in the persian Blogodomain. Berkman center research publication.

Khaniki, Hadi, Atabak, Mohammad, Azizi, Farid. (2017). "Analysis of the situation of virtual social networks in Iran with the Habermas public domain approach", Communication Culture Studies, Volume 18, Number 37.

Moghanizadeh, S. (2016). The role of social media in Iran's Green Movement. Master's Thesis in Department of Applied Information Technology Gothenburg.

Najafi, S. \& Nyblom, M. (2006). Iranian Youth and the Internet: six vioces on internet use beyond the public and private domains. Master's Thesis in Stockholm school of Economics, Retrieved from: www.arc.hhs.se.

Najafi, S. \& Nyblom, M. (2016). Iranian Youth and the Internet: six vioces on internet use beyond the public and private domains. Master's Thesis in Stockholm school of Economics, Retrieved from: www.arc.hhs.se.

Naqib Sadat, Seyed Reza. (2012). Public domain in cyberspace, Social Sciences Quarterly No. 57. 
peyro, Fariborz; Mottaqi, Ebrahim and Nawabakhsh, Mehrdad. (2018). Sociological analysis of the role of Telegram social media as a public domain in the elections of the 10th term of the Islamic Consultative Assembly of Iran, a case study of Tehran. Sociology of Social Institutions, Volume 5 / Number 12.

Rezania, Awat. (2010). Internet and Public Domain, Case Study: Analysis of Goftman Website, Taken from Hamshahri Research Institute Website at: www.hccmr.com

Shahabi, Mahmoud and Ghodsi Bayat. (2012). Members' goals and motivations of users in virtual social networks) A study on the Quarterly Journal of Communication Culture Studies) Tehran Youth 20: 86-61.

Sreberny, Annabelle and Khiabany, Gholam. (2010). Blogistan: The Internet and Politics in Iran. London: I.B. Tauris.

Yazdkhasti, Behjat, Adlipour, Samad, Sepehri, Asia. (2013). "Content Analysis of Facebook Social Network Pages and Groups with Habermas Public Domain Theory" Iranian Social Studies and Research / Volume 2, Number 1.

Zhang, Yan; wildemuth, barbar. (2017). Qualitative Analysis of Content. In ils. Unc. Edu. 